\title{
Classification and Identification of Integrated Development Types of Urban and Rural Transportation
}

\author{
Yiming Zhou 1, a , Qingge Pang 2, b \\ ${ }^{1}$ China academy of transportation sciences, Beijing, 100029, China; \\ ${ }^{2}$ China academy of transportation sciences, Beijing, 100029, China. \\ a30959709@qq.com, b55734906@qq.com
}

\begin{abstract}
In this paper, the development types of urban and rural transportation integration are divided into different regions in China. On the basis of analyzing the economic and social development level and the actual situation of the integrated development level of urban and rural traffic and transportation in typical areas of China, this paper selects a mathematical model for comprehensive evaluation of regional development differences, and constructs a set of methods to identify the types of urban and rural transportation integration development, and the areas with similar basic conditions are similar. It is divided into the same type, and the typical characteristics and attributes of various types of areas are analyzed, so that the local development environment and basic development level can be fully grasped, the direction of development is scientifically and rationally formulated, and the equalization of urban and rural traffic and transportation services will be promoted step by step.
\end{abstract}

Keywords: Urban and rural transportation, integrated, development type.

\section{Introduction}

According to the present situation of urban and rural development in China, the integrated development types of urban and rural transportation can be divided into three categories: the urbanrural integration type, the urban-rural cross type, and the urban-rural segmentation type. In view of the fact that there Chinese around the actual development situation, road traffic conditions, terrain conditions etc., as the differences between regions are put forward to integrated development pattern, specially constructed for identification index system integration development type. Based on the actual data of several districts and counties in China, the data model used to evaluate the regional development differences is selected, and the K-cluster clustering analysis is adopted to cluster the comprehensive evaluation value of the district and county, and the areas with similar basic conditions are classified into one type, and the types of the types are analyzed.

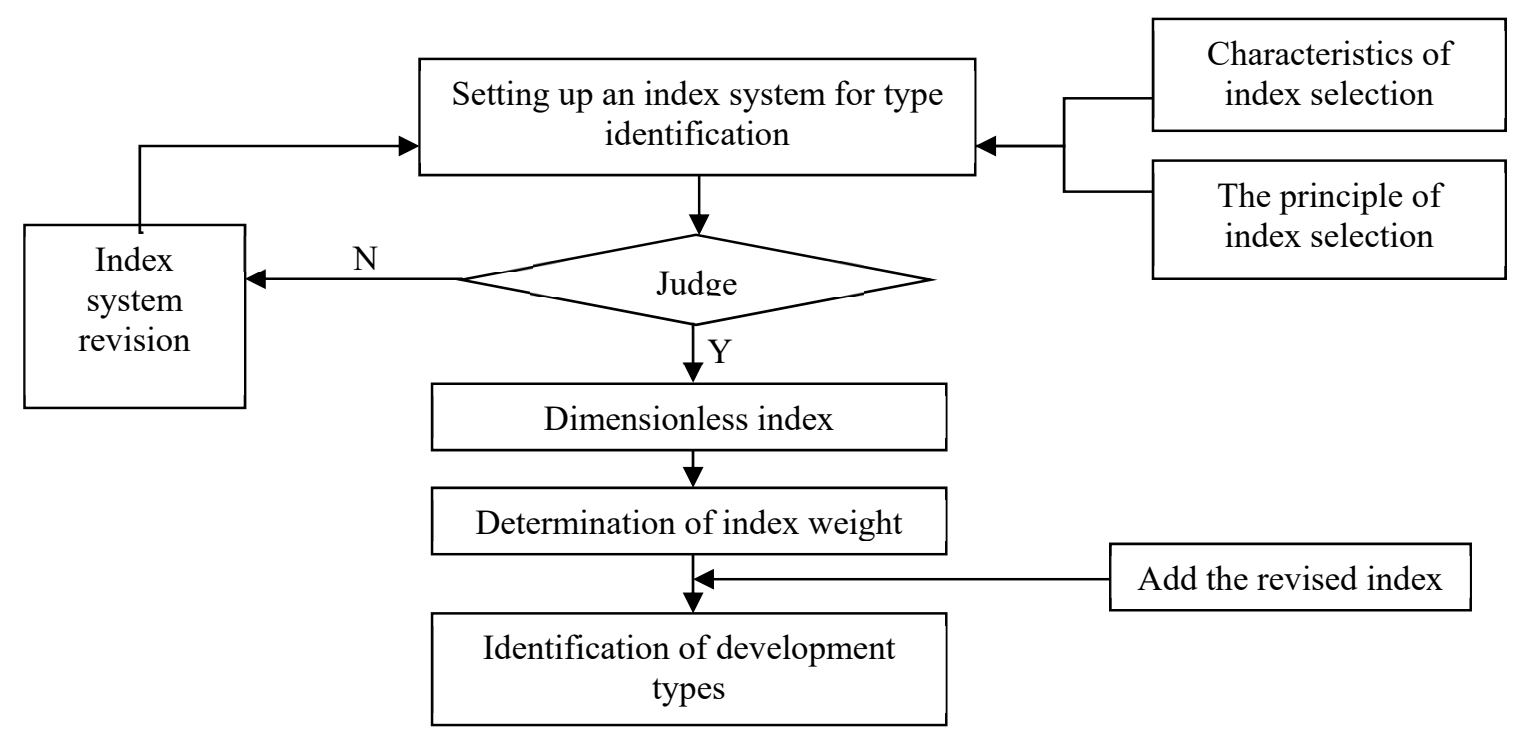

Fig. 1 Specific ideas for the identification of development types 


\section{Classification of Development Types of Urban and Rural Transportation Integration}

\subsection{The Urban-rural Integration Type.}

This type refers to the areas with relatively good economic foundation, relatively high degree of urbanization, large population density, and strong intensity of passenger and freight traffic. These areas have basically realized all areas and counties covered by traffic infrastructure networks, with high level of development, balanced development, concentration of population, significant advantages in traffic location and rapid economic development.

Most of the districts and counties in this type have been urbanized. Passenger demand is reflected in urban and public transport, public transport and urban and rural passenger transport. Freight demand is reflected in the development of regional industry, mass production and transportation of goods and materials. This type of districts and counties should focus on optimizing the allocation of passenger and freight traffic resources and improving the depth of network services. It is necessary to further improve the hardware and software facilities and external environment of the whole area bus integration and urban and rural logistics system.

\subsection{The Urban-rural Cross Type.}

This type refers to the areas with relatively good economic foundation, relatively high urbanization rate and relatively large population density. These areas have a certain traffic infrastructure network base, or have strong influence central urban area, moderate area, relatively concentrated population, a certain traffic location advantage and great economic development potential

The urban and rural areas in this type are coordinated and developed rapidly, and the interaction between urban and rural areas is greater. Passenger demand is not only reflected in the urban and rural public transport, but also on the mode of passenger transport between urban and rural areas. Freight demand is reflected in the establishment of urban and rural integration of logistics service system. This type of district and county needs to promote the transformation of the operation mode steadily in order to improve the cohesion efficiency, promote the development of rural passenger transport, promote the integration and development of urban rural logistics, and cultivate urban and rural passenger and cargo. It is suggested that the urban and rural traffic operation mode, supplemented by rural passenger transport and rural logistics special line, is based on urban public transport, urban logistics and distribution extension and rural passenger transport "bus" operation. We should focus on the link between the rural and urban areas to meet the needs of mutual exchanges between the urban and rural areas.

\subsection{The Urban-rural Segmentation Type.}

This type refers to the counties with poor economic foundation, low urbanization rate and small population density. The development of road infrastructure in these areas is lagging behind, the demand for passenger and cargo is not stable, the area is large, the distribution of the population is scattered, the terrain is complex, the location advantage is not obvious, and the economic development potential is weak.

The development of urban and rural areas in this type of area is relatively divided, and some rural areas are relatively backward, and there is less demand for transportation in urban and rural areas. The main demand of urban and rural transportation is reflected in the basic supply of urban and rural passenger and freight transport. Such areas need to focus on accelerating development so as to increase investment in transportation resources, strengthen network coverage and enhance the overall accessibility of transportation networks. It is suggested that the urban and rural transportation operation mode, which is mainly based on the full coverage of urban and rural transportation and regional operation, should be adopted. These areas should focus on improving the service level of rural traffic and transportation services to urban and rural residents, promoting the equalization of basic services for urban and rural transportation, and meeting the demand for passenger and freight transportation of rural residents. 


\section{Research on the Method of Development Type Recognition}

\subsection{Construction of Type Identification Index System.}

\subsubsection{Subject Index}

Based on the system theory and the relationship between urban and rural traffic and regional economic and social development, the county level area is taken as the research unit. Standing on a macro point of view of the integration of urban and rural transport is based on the economic and social development in the region. The level of economic and social development determines to a great extent the speed and difficulty of promoting the development of urban and rural transportation in the region, and also determines the way, quality and the demand of urban and rural logistics for urban and rural residents to enjoy travel services. So, in the choice of the main indicators, the first choice is related to economic and social indicators, faster and more intuitive to reflect the differences in the development of different regions. Secondly, in view of the economic and social development of urban and rural transportation, the number, living standard and consumption structure of urban and rural residents are closely related to the development of traffic, so the human factors should be considered, especially the relationship with economic and social development. Finally, indicators for the current level of transport development in counties and regions should also be considered. Therefore, when constructing the index system, we should select relevant indicators such as economic, social and transportation development as the main indicators to reflect the differences in regional development.

The level of regional economic development

The level of regional economic development is the foundation for ensuring sustainable development of urban and rural traffic. The size of the GDP not only reflects the strength of regional economic strength, but also determines the mode of travel and service quality of urban and rural residents and the demand for the circulation of goods and goods in urban and rural areas. In order to show the impact of this aspect in a timely manner, using the international experience, selecting the per capita GDP index, it can not only reflect the economic strength of a certain region, but also reflect the economic differences between the regions. The acquisition of index data is relatively easy, and has certain practical operational significance.

The level of regional social development

The urbanization rate is commonly used to reflect the process and degree of aggregation of population to urban agglomeration. In addition to representing the economic and social development of a region, the urbanization rate is also an important sign to measure the degree of social organization and management level in a region. The urbanization rate can also serve as a key indicator for the change of passenger and freight volume in urban and rural areas. Therefore, we should choose the urbanization rate as an indicator to reflect the social development level of the region.

Regional population distribution

The layout of urban and rural transport infrastructure and the layout of passenger and freight lines and sites are closely related to the distribution of population in a region. The population density is often used to reflect the distribution of the population in a region, and also to measure the mode of operation and organization for urban and rural transportation in a region, as well as the difficulty of opening the rural passenger lines and providing urban and rural logistics services. Therefore, we choose population density as an indicator to reflect the distribution of population in the region.

The level of road traffic development

The current level of road traffic development is the material basis for promoting the integrated development of urban and rural transportation. The road patency rate of administrative villages can reflect the scale of road construction in a district, and also reflects the depth of road network to some extent. Therefore, it is of great practical significance to choose the road patency rate of administrative villages as an index to reflect the level of road traffic development.

\subsubsection{Correction Index}

Although the integration of urban and rural traffic and transportation is based on the development of regional economic and social development, but the basic conditions, such as geographical 
conditions, development potential and other aspects if it does not adapt to the development of urban and rural traffic, then the integrated development will not be sustainable. Based on this, the topographic landform index and the development potential index are proposed as the correction index of the main index, which can be used to correct the comprehensive value of the different county regions in order to ensure the accuracy of the identification of the development types in a certain area.

The topographic and geomorphic indicators

The topographic and geomorphic indexes are mainly aimed at the different characteristics of the urban and rural traffic development because of the different geographical conditions and traffic location, especially a revised index. For example, the development advantages of mountainous areas are worse than those in plain areas, the development advantages of areas with advantages in transportation location are better than those with poor transport location. The index is a qualitative indicator, after obtaining the first result of regional type recognition, we use the index to re check all districts and counties, and strive to make regional type recognition more reasonable.

The development potential index

The development potential index is a comprehensive index to measure the future development of counties and districts. This index is a qualitative indicator, the determination of the index is to reassess the districts and counties by combing the state (or regional) level, the provincial level and the local level of development strategy and planning, to judge the impetus and speed of the future development, and to predict the advantages and hindrance of the integration of urban and rural transportation and transportation in the future.

\subsection{Mathematical Model for Type Recognition.}

Drawing on the results of regional development differences, we use the mathematical model of comprehensive evaluation of regional development gap as a mathematical model for identifying regional types. Combined with analytic hierarchy process, expert consultation and K-cluster clustering analysis, the county regions are classified reasonably. In this system, three mathematical models are applied to determine the index weight system. The following is a description of the mathematical models used in type recognition.

\subsubsection{Determine the Subject Index and the Correction Index}

Subject indicators include Per capita GDP $\mathrm{A}_{1}$ (yuan per person), Urbanization rate $\mathrm{A}_{2}(\%)$, Population density $\mathrm{A}_{3}$ (people per square kilometer) and Patency of road $\mathrm{A}_{4}(\%)$. The correction indicators include Topographic and geomorphic indexes $\mathrm{B}_{1}$, and development potential index $\mathrm{B}_{2}$.

\subsubsection{Dimensionless Subject Index}

$$
a_{i}=A_{i} / \overline{A_{l}}, i=1,2,3,4
$$

$a_{i}$ is the main index of dimensionless;

$A_{i}$ is the main body index;

$\overline{A_{l}}$ is the standard value of the main target, of which, $\overline{A_{1}}=50000$ yuan per person; $\overline{A_{2}}=60 \%$; $\overline{A_{3}}=450$ people per square kilometer; $\overline{A_{4}}=90 \%$.

\subsubsection{Determining the Weight of the Subject Index}

The empowerment method based on the principle of "function driven"

The formula of weight coefficientp $i(\mathrm{i}=1,2,3,4)$ is based on the "function driven" principle:

$$
\begin{gathered}
\mathrm{p}_{\mathrm{i} 1}=\mathrm{A}_{\mathrm{i} 1} / \sum_{\mathrm{j}=1}^{4} \mathrm{~A}_{\mathrm{ij}}(\mathrm{j}=1,2, \ldots 4) \\
\mathrm{p}_{1}=\frac{\sum_{\mathrm{i}=1}^{\mathrm{m}} \mathrm{p}_{\mathrm{i} 1(\mathrm{i}=1,2, \ldots \mathrm{m})}}{\mathrm{m}}
\end{gathered}
$$




$$
\begin{gathered}
\mathrm{p}_{\mathrm{i} 2}=\mathrm{A}_{\mathrm{i} 2} / \sum_{\mathrm{j}=1}^{4} \mathrm{~A}_{\mathrm{ij}}(\mathrm{j}=1,2, \ldots 4) \\
\mathrm{p}_{2}=\frac{\sum_{\mathrm{i}=1}^{\mathrm{m}} \mathrm{p}_{\mathrm{i} 2(\mathrm{i}=1,2, \ldots \mathrm{m})}}{\mathrm{m}} \\
\mathrm{p}_{\mathrm{i} 3}=\mathrm{A}_{\mathrm{i} 3} / \sum_{\mathrm{j}=1}^{4} \mathrm{~A}_{\mathrm{ij}}(\mathrm{j}=1,2, \ldots 4) \\
\mathrm{p}_{3}=\frac{\sum_{\mathrm{i}=1}^{\mathrm{m}} \mathrm{p}_{\mathrm{i} 3(\mathrm{i}=1,2, \ldots \mathrm{m})}}{\mathrm{m}} \\
\mathrm{p}_{\mathrm{i} 4}=\mathrm{A}_{\mathrm{i} 4} / \sum_{\mathrm{j}=1}^{4} \mathrm{~A}_{\mathrm{ij}}(\mathrm{j}=1,2, \ldots 4) \\
\mathrm{p}_{4}=\frac{\sum_{\mathrm{i}=1}^{\mathrm{m}} \mathrm{p}_{\mathrm{i} 4(\mathrm{i}=1,2, \ldots \mathrm{m})}}{\mathrm{m}}
\end{gathered}
$$

$p_{i 1}$ is the function driving weight coefficient of per capita GDP in county $i, A_{i 1}$ is the per capita GDP in the County I;

$p_{i 2}$ is the function driving weight coefficient of urbanization rate in county $i, A_{i 2}$ is the urbanization rate in the County $\mathrm{i}$;

$\mathrm{p}_{\mathrm{i} 3}$ is the function driving weight coefficient of population density in county $\mathrm{i}, \mathrm{A}_{\mathrm{i} 3}$ is the population density in the County $\mathrm{i}$;

$\mathrm{p}_{\mathrm{i} 4}$ is the function driving weight coefficient of road patency in county $\mathrm{i}, \mathrm{A}_{\mathrm{i} 4}$ is the road patency in the County $\mathrm{i}$;

$\mathrm{M}$ is the sample number of all districts and counties participating in the assessment.

The empowerment method based on the principle of "difference driven"

The formula of weight coefficienta ${ }_{i}(\mathrm{i}=1,2,3,4)$ is based on the "difference driven " principle:

$$
s_{i j}^{2}=\sum_{j=1}^{4} \frac{\left(x_{i j}-\overline{x_{i}}\right)^{2}}{4}, \overline{x_{i}}=\sum_{j=1}^{4} x_{i j} / 4(j=1,2, \ldots, 4)
$$

$\mathrm{S}_{\mathrm{ij}}$ is the coefficient of mean square variance of each index, $\overline{\mathrm{X}_{\mathrm{i}}}$ is the average value of the dimensionless value of the 4 main indicators of I County, $s_{i j}^{2}$ is the variance of each index, $x_{i j}$ is the dimensionless value of the first $\mathrm{j}$ index of the county $i$.

$$
\begin{gathered}
\mathrm{q}_{\mathrm{i} 1}=\mathrm{s}_{\mathrm{i} 1} / \sum_{\mathrm{j}=1}^{4} \mathrm{~s}_{\mathrm{ij}}(\mathrm{j}=1,2, \ldots 4) \\
\mathrm{q}_{1}=\frac{\sum_{\mathrm{i}=1}^{\mathrm{m}} \mathrm{q}_{\mathrm{i} 1(\mathrm{i}=1,2, \ldots \mathrm{m})}}{\mathrm{m}}
\end{gathered}
$$




$$
\begin{gathered}
\mathrm{q}_{i 2}=\mathrm{s}_{i 2} / \sum_{\mathrm{j}=1}^{4} \mathrm{~s}_{\mathrm{ij}}(\mathrm{j}=1,2, \ldots 4) \\
\mathrm{q}_{2}=\frac{\sum_{\mathrm{i}=1}^{\mathrm{m}} \mathrm{q}_{\mathrm{i} 2(\mathrm{i}=1,2, \ldots \mathrm{m})}}{\mathrm{m}} \\
\mathrm{q}_{i 3}=\mathrm{s}_{\mathrm{i} 3} / \sum_{\mathrm{j}=1}^{4} \mathrm{~s}_{\mathrm{ij}}(\mathrm{j}=1,2, \ldots 4) \\
\mathrm{q}_{3}=\frac{\sum_{\mathrm{i}=1}^{\mathrm{m}} \mathrm{q}_{\mathrm{i} 1(\mathrm{i}=1,2, \ldots \mathrm{m})}}{\mathrm{m}} \\
\mathrm{q}_{i 4}=\mathrm{s}_{\mathrm{i} 4} / \sum_{\mathrm{j}=1}^{4} \mathrm{~s}_{\mathrm{ij}}(\mathrm{j}=1,2, \ldots 4) \\
\mathrm{q}_{4}=\frac{\sum_{\mathrm{i}=1}^{\mathrm{m}} \mathrm{q}_{\mathrm{i} 4(\mathrm{i}=1,2, \ldots \mathrm{m})}^{\mathrm{m}}}{}
\end{gathered}
$$

$\mathrm{q}_{\mathrm{i} 1}$ is the driving force coefficient for the difference of GDP per capita in counties $\mathrm{i}, \mathrm{S}_{\mathrm{i} 1}$ is the per capita GDP mean square variance coefficient of the County $\mathrm{i}, \mathrm{q}_{\mathrm{i} 2}$ is the difference driving weight coefficient of urbanization rate in counties $i, S_{i 2}$ is the mean square deviation coefficient of the urbanization rate in the County $\mathrm{i}, \mathrm{q}_{\mathrm{i} 3}$ is the driving force coefficient of population density difference in county $\mathrm{i}, \mathrm{S}_{\mathrm{i} 3}$ is the mean variance coefficient of population density in the first County $\mathrm{i}, \mathrm{q}_{\mathrm{i} 4}$ is the difference driving weight coefficient of highway patency in county $\mathrm{i}, \mathrm{S}_{\mathrm{i} 4}$ is the road unobstructed rate mean square variance coefficient in the County i.

Comprehensive integrated weighting method

Integrated weighting coefficient of integrated empowerment $\omega_{i}(\mathrm{i}=1,2,3,4)$ :

$$
\omega_{i}=\mathrm{p}_{\mathrm{i}} \mathrm{q}_{\mathrm{i}} / \sum_{\mathrm{i}=1}^{4} \mathrm{p}_{\mathrm{i}} \mathrm{q}_{\mathrm{i}}(\mathrm{i}=1,2, \ldots, 4)
$$

\subsubsection{Establishing the Model Formula}

$$
S_{0}=\omega_{i} a_{i}+\mu_{1}+\mu_{2}(\mathrm{i}=1,2, \ldots, 4)
$$

$S_{0}$ is a region type identification value, $\mu_{1}, \mu_{2}$ are correction coefficients corresponding to the modified values B1 and B2 respectively. The terrain in the region is good, general and poor, the value of $\mu_{1}$ is $0.1,0$, and -0.1 . The potential for economic development in the region is large, general and poor, the values of $\mu_{2}$ are $0.1,0$, and -0.1 .

\subsubsection{Criteria for Judging Development Types}

After obtaining the quantitative value of the integrated development of urban and rural transportation, it is necessary to classify the development types of all counties. County districts can 
judge their own models suitable for development, and they can also get a general judging standard. In 2017, The GDP per capita, the urbanization rate, the population density, the highway patency of the administrative village, the terrain and the development potential of the 2856 counties (regions) in China have been collected. The evaluation values of regional development types are calculated respectively, and then the K-means cluster analysis model is used to calculate the quantitative standard of urban and rural transportation integration development type, in order to judge the type of regional development.

When $\mathrm{S}_{0}>1$, the region is the urban-rural integration type;

When $0.5<\mathrm{S}_{0} \leq 1$, the region is the urban-rural cross type;

When $\mathrm{S}_{0} \leq 0.5$, the region is the urban-rural segmentation type.

\section{References}

[1]. Hull, A. Integrated Transport Planning in the UK: From concept to reality. Journal of Transport Geography. Vol. 13(2005) No.4, p. 318-328.

[2]. Wang Zhi, Xiao DianLiang, Tian YuJia. The Integration of Urban and Rural Public Transportation Operation. The 2nd International Conference on Intelligent Computing Technology and Automation. 2009, p. 817-821.

[3]. Tang Reqing, et al. Integration of Chongqing road passenger transport under the background of urban-rural integration. Intellectual Property Publishing House,2014, p. 51-63.

[4]. Sheng Yong: Study on integrated development strategy of urban and rural transportation at county level (D, Chang'an University, China,2011). p.25-34. 